doctors is at the core of the practice of medicine and is an important determinant of consultation behaviour and clinical care. Hannay made us familiar with the symptom iceberg, ${ }^{3}$ although only one in 40 symptoms becomes the subject of a medical consultation. ${ }^{45}$ The severity of symptoms is a poor predictor of a patient's likelihood to consult a general practitioner; studies of gastrointestinal symptoms have shown that concern about the implications of symptoms for serious or life threatening disease operates as a trigger to consultation. ${ }^{6}$ Thomas made the crucial observation that in up to $40 \%$ of patients seen in genera practice it is impossible to make a firm physica diagnosis and that most of these patients recover completely and spontaneously; Thomas coined two telling phrases to describe this work - "the temporarily dependent patient" ${ }^{\text {" }}$ and "the therapeutic illusion."

In general practice we are concerned to make early and accurate diagnoses of important illness and to avoid unnecessary investigation of minor and self limiting disorders. To answer the question "Well, if it's not serious then what is it?" we use what Dixon dubbed diagnostic black boxes, which apparently explain problems as long as you do not inquire into the mechanism too closely. ${ }^{9}$ Terms such as "a virus," "sprains," and "fibrositis" help to identify otherwise unidentifiable disorders and point the way to non-intervention.

The last piece of the jigsaw was provided by Thomas ${ }^{10}$; in patients in whom no definite diagnosi could be made a "positive consultation" (in which a definite dignosis was nevertheless given) was associated with greater patient satisfaction and a higher recovery rate than an artificially "negative consultation."

Cohen's patients will undoubtedly benefit from his diagnostic certainty. A particularly elegan path between candour and paternalism was taken by the eminent specialist in the apocrypha quotation: "You want to know what's wrong. Well, it's not a condition to which we doctors can yet exactly put a name. But I want you to know this. You've come to the very best man in Britain for it."

ROGER JONES

Primary Health Care,

University of Newcastle upon Tyne,

Newcastle upon Tyne NE2 4HH

1 Cohen SI. Medically unexplained physical symptoms. $B M f$ 1991;303:1062. (26 October.)

2 Scott AJ. Diagnostic accuracy would be improved by developin more categories of "non-disease" Med Hypotheses 1977;3: more

3 Hannay DR. The iceberg of illness and trivial consultations. f R Coll Gen Pract 1980;30:551-4.

Morrell DC, Wate CJ. Symptoms perceived and recorded by patients. $\mathcal{F} R$ Coll Gen Pract 1976;36:398-403.

5 Freer CB. Self-care: a health diary study. Med Care 1980;18: $853-61$

6 Lydeard S, Jones R. Factors affecting the decision to consult with dyspepsia-comparison of consulters and non-consulters. I $R$ Coll Gen Pract 1989;39:495-8.

7 Thomas KB. Temporarily dependent patient in general practice. BMf 1974;i:625-6.

8 Thomas KB. The consultation and the therapeutic illusion BMF 1978;i:1327-8.

9 Dixon AS. "There's a lot of it about": clinical strategies in family practice. $\mathcal{F} R$ Coll Gen Pract 1986;36:468-71.

10 Thomas KB. General practice consultations: is there any point in being positive? $B M \mathcal{F} 1987 ; 294: 1200-2$.

\section{Passive smoking and otitis media with effusion}

SIR, - The fact that G S Barr and A P Coatesworth found no association between parental smoking and otitis media with effusion shows that this difficult but important question is far from being completely answered. ${ }^{1}$ Although in their casecontrol study they matched for age, sex, and social class, it is not clear over what period the two groups were collected. Children examined during the winter are more likely to have a middle ear effusion, and this may have affected the results unless the two groups of children were collected simultaneously.

The balance of evidence from clinical studies points increasingly to an association between passive smoking and otitis media with effusion. When I compared a group of 115 children undergoing insertion of grommets for otitis media with effusion with a control group of 36 children from an orthoptic clinic I found a significant association between passive smoking and the need for grommets. Although this was not a case-control study, no significant differences were found between the two groups of children with regard to sex, age, or social class distribution.

The Edinburgh study of 892 schoolchildren aged 7 also quoted in Barr and Coatesworth's paper shows an association between results of tympanometry suggestive of a middle ear effusion and passive smoking. The Edinburgh group concluded that in their study about one third of the cases of middle ear effusion were attributable to exposure to tobacco smoke. ${ }^{3}$ I agree with Barr and Coatesworth that tympanometry alone is not an absolute indicator of the presence of a middle ear effusion, but when efforts are made to exclude results showing high canal volumes (indicating a perforation of the tympanic membrane) and very low canal volumes (indicating a probe blocked with wax) a flat tympanogram is highly suggestive of a middle ear effusion.

Experimental studies are yielding further insights into a possible causative link between tobacco smoke and middle ear effusions. Constituents of tobacco smoke may lead to cilia dysfunction, ${ }^{4}$ and an experimentally induced reduction in middle ear cilial function may lead to the production of a middle ear effusion.

Obviously, further research is warranted to confirm the probable relation between parental smoking and otitis media with effusion, and experimental studies are needed to explain the mechanism of any causative link.

ANTHONY HINTON

Department of Otolaryngology,

Hospital for Sick Children, Great Ormond Street,

London WCIN 3JH

1 Barr GS, Coatesworth AP. Passive smoking and otitis media with effusion. BM7 1990;303:1032-3. (26 October.)

2 Hinton AE. Surgery for otitis media with effusion in children and its relationship to parental smoking. F Laryngol Otol 1989;103: its relations.

3 Strachen DP, Jarvis MJ, Feyerabend C. Passive smoking, salivary cotinine concentrations, and middle ear effusions in salivary cotinine concentrations, and middl
7 year old children. $B M \mathcal{F}$ 1989;298:1549-52.

4 Sisson JH, Tuma DJ, Rennard SI. Acetaldehyde-mediated cilia dysfunction in bovine bronchial epithelial cells. Am $\mathcal{F}$ Physiol 1991;260:29-36

5 Ohashi Y, Nakai Y, Furuya H, Esaki Y, Ikeoka H, Kato S, et al. Mucociliary disease of the middle ear during experimental otitis media with effusion induced by bacterial endotoxin. Ann Otol Rhinol Laryngol 1989;98:479-84.

\section{European health challenges}

SIR, - The World Health Organisation's Health for All programme targets differences in health status between groups within countries. The aim is a $25 \%$ improvement in the health of the disadvantaged group (target 1). In Tony Smith's article on European health challenges differences between sexes are referred to only in terms of life expectancy. ${ }^{i}$ Other evidence suggests that it is reasonable to target men as a particularly disadvantaged group. The Black report showed that the ratio of death rates for 15-64 year old men compared with women was 1.9 in 1971 , but it did not have sex differences within its mandate. ${ }^{2}$ This compared with a ratio of 2.5 for social class $V$ compared with social class I. At the same time men's consultation patterns lead to fewer opportunities for doctors to be involved directly with the target population.

Although morbidity and mortality among men and women can be aptly summarised as "women suffer while men die," mortality statistics for men demand that men be treated as a disadvantaged group and targeted accordingly. This targeting must begin early while health behaviour is being established ${ }^{4}$ as at an early age boys are more likely than girls to expect to remain healthy. ${ }^{5}$

The disadvantages of the sexes are as serious as those associated with the different social classes and must be targeted likewise.

Ullevål Sykehus,

SIMON R WILKINSON

0407 Oslo 4 , Norway

1 Smith T. European health challenges. BMf 1991;303:1395-8. (30 November.)

2 Townsend $\mathrm{P}$, Davidson N. Inequalities in health. Harmondsworth: Penguin, 1982:57.

3 Blaxter M. Equity and consultation rates in general practice. BMF 1984;288:1963-7.

4 Wilkinson SR. The child's world of illness: the development of health and illness behaviour. Cambridge: Cambridge University Press, 1988.

5 Gochman DS. Children's perceptions of vulnerability to illness and accidents. Public Health Rep 1970;85:69-73.

\section{Preventing AIDS now}

SIR,-Robert J Biggar indicated that resistance to using condoms in many countries is due to reduced sexual pleasure, the belief that condoms encourage promiscuity, and religious or cultural beliefs. In a pilot study we found evidence suggesting that lack of knowledge regarding the effectiveness of condoms should be added to that list.

We performed a study in February 1991 at the Aga Khan Hospital, Nairobi, which draws patients mainly from social classes I, II, and III, the educated and wealthy classes. We interviewed 50 medical patients using a standard questionnaire. Twenty six were positive for HIV antibodies (four were unaware of their diagnosis) and 24 were negative for HIV antibodies or had not been tested. Only one patient refused to participate.

Knowledge regarding the risk of HIV transmission was good for some aspects and poor for others (table). Most worrying was the fact that only $55 \%$ believed condoms prevented the transmission of HIV infection. Furthermore, several patients also voiced concern about the risk of condoms splitting.

More effective health promotion strategies

Knowledge regarding HIV transmission in 49 Kenyan patients

\begin{tabular}{|c|c|c|c|}
\hline \multirow[b]{2}{*}{ Route of transmission } & \multicolumn{3}{|c|}{$\begin{array}{l}\text { No of patients } \\
\text { responding }\end{array}$} \\
\hline & Yes & No & $\begin{array}{l}\text { Don't } \\
\text { know }\end{array}$ \\
\hline Blood transfusion & 47 & 1 & 1 \\
\hline Sterile needle & 6 & 39 & 4 \\
\hline Used needle & 49 & & \\
\hline Donating blood & 19 & 27 & 3 \\
\hline Sharing a cup & 8 & 36 & 5 \\
\hline Handshake & 1 & 47 & 1 \\
\hline Kissing & 19 & 26 & 4 \\
\hline Breast milk & 24 & 7 & 18 \\
\hline Vaginal sexual intercourse & 48 & & 1 \\
\hline Oral sexual intercourse & 20 & 14 & 15 \\
\hline Anal sexual intercourse & 27 & 3 & 19 \\
\hline Masturbation of partner & 15 & 25 & 9 \\
\hline Vaginal sexual intercourse with condom & 18 & 27 & 4 \\
\hline
\end{tabular}

regarding safe sex need to be developed and it is vital that this is accompanied by the ready availability of high quality condoms.

K E ROGSTAD

I H AHMED-JUSHUF

Department of Genitourinary Medicine,

City Hospital, Nottingham NG5 IPD

L TESFA

M S ABDULLAH

Department of Medicine,

Aga Khan Hospital

Nairobi, Keny

1 Biggar RJ. Preventing AIDS now. BMf 1991;303:1150-1. (9 November.) 